\title{
Syntactic and Prosodic Processing of Quantifier Ambiguity in Turkish
}

\author{
Cemre Ece Kırcal1 ${ }^{1 *}$, İpek Pınar Uzun ${ }^{* *}$, \& Özgür Aydın ${ }^{* *}$
}

\begin{abstract}
In this study, we investigated how the effects of interpretation bias in the processing of universal and existential quantifiers interact with the effects of focus and linearity using a web-based sentence-picture matching experiment. We tested if sentences with $a(n)$-every order are processed differently than sentences with every$a(n)$ order in the interpretation of Turkish sentences designed to be biased toward either collective or distributive readings. This study also examined whether focused quantifiers are processed differently than non-focused quantifiers in the interpretation of Turkish sentences designed to be biased toward either collective or distributive readings. Our stimuli consisted of 120 sentences. The design of the experiment * was a two-by-two within-subject factorial design with independent variables of ORDER (every-a(n) vs. $a(n)$-every) and FOCUS (focused existentials vs. focused universals), and their interactions. Native speakers of Turkish $(n=75)$ listened to sentences that were biased towards either collective or distributive readings. Then, the participants matched pictures that were either congruent or incongruent with these biased sentences. Our findings indicated that the collective interpretation with $a(n)$-every order was more acceptable than the distributive interpretation, while there was a greater tendency toward interpreting the sentences with every- $a(n)$ order as distributive. Prosody also affected the interpretation of doubly quantified sentences with every-a(n) order. Our reaction time findings, on the other hand, indicated that computing the interpretation of sentences with every- $a(n)$ order involved significantly more cognitive load than computing the interpretation of sentences with $a(n)$-every order.
\end{abstract}

Keywords. quantifier scope, focus, scope rigidity, interpretation, Turkish

1. Introduction. It has been widely discussed how the resolution of universal $(\forall)$ and existential $(\exists)$ quantifier ambiguities can occur among languages both syntactically and semantically. In this paper, we investigate the syntactic and prosodic effects in the disambiguation processes of doubly quantified sentences in Turkish. The fact that there are two possible interpretations of sentences such as (1a) indicates that the inverse scope reading is available in Turkish (Göksel, 1998; Gürer, 2015; Kelepir; 2001, Kural, 1992; Altınok, 2017). The surface scope $(\forall>\exists$ ) implies the distributive reading (salient reading), indicating that for every girl there are (possibly different) movies that they watch. On the other hand, inverse scope $(\exists>\forall)$ reading establishes a collective reading, which means that there is a specific movie that all girls watch. The inverse scope reading in (1a) is available in only certain constructions with the accusative case marking indefinite direct objects that are ambiguous between a wide scope reading and a narrow scope reading (Aygen-Tosun, 2007;

\footnotetext{
* First Author: Cemre Ece Kircalı, Dokuz Eylül University, Department of Linguistics (c.ecekircali@gmail.com).

** Corresponding Author: İpek Pınar Uzun, Ankara University, Department of Linguistics, Neuroscience and Neurotechnology Center of Excellence (bekar@ankara.edu.tr) \& Third Author: Özgür Aydın, Ankara University, Department of Linguistics, Neuroscience and Neurotechnology Center of Excellence (aydio@ankara.edu.tr).

* This study was supported by the Scientific and Technological Research Council of Turkey (TÜBİTAK) Project 1002 (number 119K761). The study was approved by the Ethical Board of the Ankara University (number İ2-5419, 18 July 2019). We are grateful to Kerem Tütüncü for his help in stimulus illustration and to two anonymous reviewers for their valuable comments.
} 
Enç, 1991; Kelepir, 2001; Kural, 1992). An unmarked direct object as in (1b), however, can only have a narrow scope reading (Kelepir, 2001:84). According to Enç (1991), an accusative indefinite object taking scope over a universal operator makes inverse scope available as in (1a), while the object in sentence (1b) cannot take wide scope because it is not specific. On the other hand, in (2), where the indefinite subject bir klz 'a girl' precedes the universal quantifier object her filmi 'every movie,' the only possible reading seems to be the wide scope reading (Göksel, 1998). Based on such examples, Göksel (1998) claimed that linearity plays a role in the scope of quantifiers in Turkish.

$$
\begin{aligned}
& \text { a. Her k1z bir filmi } \\
& \text { every girl.NOM a movie.ACC } \\
& \text { 'Every girl watched a movie' }
\end{aligned}
$$
b. Her k1z bir film every girl.NOM a movie 'Every girl watched a movie'

izledi. $(\forall>\exists, \exists>\forall)$

watch.PAST.3S

izledi. $(\exists>\forall)$

watch.PAST.3S

(2)
Bir k1z
her filmi
a girl every movie.ACC
'A girl watches every movie'
izledi. $\quad(\forall>\exists)$
watch.PAST.3s

In addition to quantifier order, prosody may also be taken to be relevant to resolution of quantifier scope ambiguities. Our study did not only consider the structural positions of the quantified phrases. It also considered whether the quantified phrases were focused or not. Sentence (3) seems to have two possible interpretations, which indicates that the inverse scope reading is still available. However, the inverse scope reading (i.e., $\exists>\forall$ ) is more easily accessible when the object is focused. On the other hand, in (4), where the existential quantifier precedes the universal quantifier, the inverse scope reading (i.e., $\forall>\exists$ ) does not seem to be available, even though its universal quantifier is focused. This is the neutral stress pattern in Turkish, where the pitch accent lies on the immediately preverbal element.

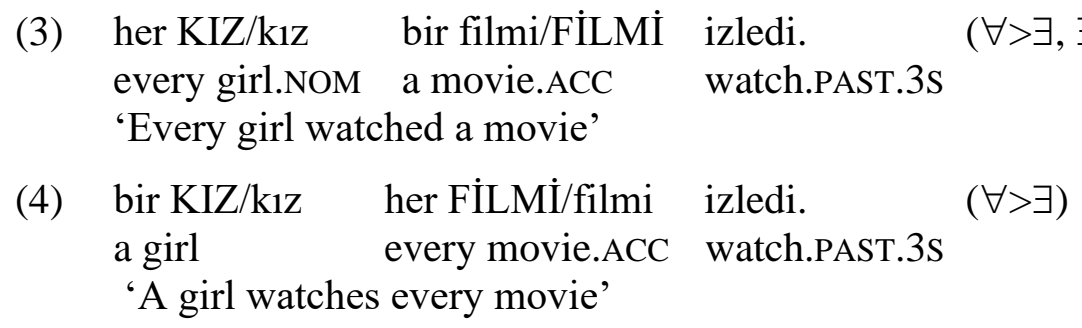

Based on the one-to-one correspondence between the linear order and the default discourse structure of Turkish, Kennelly (2003) proposed a discourse-based account for such ambiguities in which only the discourse structure is considered essential. According to Kennelly, a significant percentage of Turkish speakers do accept the inverse scope reading available for (5) in which the object is in the dative case, in contrast to (4). Kennelly argued that discourse structure rather than linearity is crucial to account for quantifier scope ambiguity in Turkish, and discourse structure reflected in prosody seems to override the default linear organization of discourse roles.
(5) Bir DOKTOR her hastaya
eşlik etti $\quad(\exists>\forall, \forall>\exists)$
A doctor.NOM every patient.DAT accompany.PAST.3S
'A doctor has accompanied every patient' 
This is the starting point for this study's investigation of whether or not prosody affects linear and inverse scope interpretations in doubly quantified sentences in Turkish. Our study also includes the restriction that doubly quantified sentences must include accusative objects.

1.1 PSYCHOLINGUISTIC EVIDENCE FOR QUANTIFIER AMBIGUITY. Linearized wide scope reading is cross-linguistically accepted, as many psycholinguistic studies have reported (e.g., Ioup, 1975; Fodor \& Sag, 1982; Dwivedi, 2013). Therefore, quantification latency becomes more salient due to semantic complexity and prosodic features when it is compared to syntactic constructions. The psycholinguistic evidence concerning ambiguity resolution contains a well-known discussion of processors' preference for a single reading, which occurs just before the perception process. Kurtzman and MacDonald (1993) conducted a well-designed study investigating the structural principles of quantifiers using syntactic positions and semantic ambiguity with four different experiments in English sentences. According to them, there are multiple strategies for encoding and decoding interpretations, which can be based both on structural principles such as scope assignment and on other processing mechanisms such as ranked-parallel models, minimal attachment, and local association.

Kurtzman and MacDonald (1993) presented various factors (e.g., context) as giving rise to these alternative strategies for quantifier resolution. Tunstall (1998) offered supporting evidence for Kurtzman and MacDonald's argument by using several types of event structures to examine quantification. Tunstall measured the reaction times (RTs) to the quantifiers every and each in English sentences. She found that the quantifier each had more distributional readings than the quantifier every. Thus, the quantifier every contains more sub-events than the quantifier each in its own semantic set within the event structure. Two recent studies of quantifier ambiguity also support Kurtzman and MacDonald. The first, an experimental study by Dotlačil and Brasoveanu (2021) supports the findings of Frazier, Lyn, Patch, and Rayner (1999), and Bott and Radó (2009). Dotlačil and Brasoveanu (2021) conducted a self-paced reading study of interpretation preferences between collective and distributive readings. They found that collective readings were available when the distributive reading was assigned by a phrasal distribution (i.e., the presence of a distributive quantifier). In the second, Zimmermann and Philipp (2020) suggested that inverse scope readings were possible in the order of existential subject-universal object (i.e., $\exists>\forall$ ) and can scramble over other readings of canonical German sentences. Researchers have thus supported Kurtzman and MacDonald's claims about the importance of context in disambiguation and the availability of alternative interpretations when the context is biased towards them.

An eye-tracking study by Filik, Paterson, and Liversedge (2004) provided evidence about the on-line processing of doubly quantified sentences with the quantifier every by manipulating the quantifier order. Filik, Paterson, and Liversedge found that the quantifier orders of every- $a(n)$ require less total reading time when compared to $a(n)$-every orders. They concluded that the reading times of plural references were longer than those singular references. Another claim about resolution of quantifier scope comes from Anderson (2004) and concerns choice of interpretation based on the surface order of quantifiers. She suggested that quantifier scope ambiguities are governed by human sentence processing mechanisms with real-time interpretations that are driven by structure.

The correspondence between syntactic and prosodic features in disambiguation has revealed similarities and differences among languages. Keller and Alexopoulou (2001) suggested that the interaction between word order (i.e., the position of the topic or focus) and prosody (i.e., accent placement) could define structural units of information such as discourse configurations for both English and Greek. Keller and Alexopoulou claimed that linearity could only take a secondary role compared to accent placement in the absence of context in 
Greek and concluded from this that there may be a minor or indirect relation between linearity and prosody to mark information structure. This view also was supported when Baltazani (2002) confirmed an indirect association between accent pattern and scope interpretation in Greek with three experiments. Baltazani showed that reconstruction (i.e., disambiguation) without context can be made available by prosodic information, but that prosody itself did not control any scope mechanism.

Surányi and Turi (2017) investigated quantificational noun phrases (QNPs) in Hungarian sentences. Their argument supported the cross-linguistic nature of wide scope interpretations, which was in line with the previous psycholinguistic studies (e.g., Anderson, 2004; Tunstall, 1998). Surányi and Turi investigated wide and narrow scopes for QNPs in the focus position and determined that readers' preferences had similar rates for wide and narrow scopes in quantification.

A recent study by Oikonomou, Golcher, and Alexiadou (2020) investigated the availability of inverse scope interpretation in Greek doubly quantified sentences with the condition of focus marking. They found that inverse scope was available in phrases that contained the broad-focus feature. Their study, like previous studies (e.g., Anderson, 2004; Brasoveanu \& Dotlačil 2019; Polinsky, Tsai and Mai, 2017; Tunstall, 1998), also supported claims about the processing cost associated with computing more complex derivations. Ionin and Luchkina's (2018) study examined the relationship between surface scope and contrastive focus. They concluded that (i) native Russian speakers preferred surface scope under neutral prosody and (ii) contrastive focus helps with the disambiguation of quantifiers for scopal interpretation.

\subsection{EMPIRICAL STUDIES ON QUANTIFIER AMBIGUITY IN TURKISH AND THE CURRENT STUDY.} Although few empirical studies of quantifier ambiguity have been conducted in Turkish, there are some guiding assumptions for the interpretation of quantification in Turkish. First, Gürer's study (2015) investigated how Turkish encodes informational units with semantic, syntactic, prosodic interfaces in quantification. Scopal interpretations of positive and negative quantifiers along with the universal quantifier her 'every' and the existential quantifier bir 'a/an,' and their focal features were examined in two on-line experiments. Gürer found that Turkish quantifiers are assigned scopes by word order, and that the wide scope interpretation of surface structure is associated with scope rigidity. She inferred that the existential quantifier bir ' $a /$ an' has a collective reading when it gets wide scope, and the universal quantifier her 'every' has both collective and distributive readings when it gets wide scope.

Another study of the interpretation of distributive readings of universal quantifiers in Turkish was conducted by Ay and Aydin (2016). They found that native Japanese speakers whose third language was Turkish allowed subject-wide interpretations in both subject-objectverb (SOV) and object-subject-verb (OSV) sentences, which indicated no cross-linguistic transfer. However, native Turkish speakers preferred the surface scope reading over the inverse scope reading in SOV and OSV sentences. Altınok's (2017) off-line acceptabilityjudgment task study was determined that inverse scope readings display scope rigidity in Turkish sentences. He claimed that scope differences were not affected by c-commands.

Our study investigates the interpretation of the syntactic and prosodic features of quantifier ambiguity in Turkish sentences using a sentence-picture matching task. Previous studies have typically examined the interpretation of the syntactic and prosodic features of quantifiers' focus marking (Altınok, 2017; Ay \& Aydın, 2016; Gürer, 2015); however, studies of the interaction between syntactic and prosodic information are still relatively sparse. First, we wanted to test the claim that attributes a crucial role to linearity in determining quantifier scope (Göksel, 1998). Therefore, we investigated how Turkish native speakers interpret 
doubly quantified sentences involving the universal and existential quantifier orders (every$a(n))$ and vice versa $(a(n)$-every). Second, we wanted to determine the effects of prosody on universal and existential quantifier combinations in Turkish. The purpose of doing so was to confirm the assumption that no single factor (i.e., linearity) induces quantifier scope on its own (see Kennelly, 2003). Thus, we focused first on the effect of prosody on the interpretation of sentences with every- $a(n)$ order involving the resolution of quantifier scope ambiguities, and then we examined interpretation processing performance by dividing the participants' responses into distributive readings (i.e., surface scope) and collective readings (i.e., surface scope), "to determine whether focus had any effect on the different readings. Our study's final goal was to determine whether the processing of sentences with every- $a(n)$ order differs from the processing of sentences with $a(n)$-every order. Here are this study's research questions:

(i) Does linearity play a crucial role in the interpretation of scope-ambiguous doubly quantified sentences in Turkish?

(ii) Does prosody have any effect on the interpretation of the scope-ambiguous doubly quantified sentences in Turkish?

(iii) Does prosody have any effect on the interpretation processing performance of the scopeambiguous doubly quantified sentences when we divide the participants' responses into distributive readings and collective readings?

(iv) Do the participants take more time to process the interpretation of Turkish sentences with every- $a(n)$ order than they take to process the interpretation of the sentences involving $a(n)$-every order?

2. Method. This study was supported by the Scientific and Technological Research Council of Turkey (TÜBİTAK) Project 1002 (number 119K761) and approved by the Ankara University Ethics Board (number İ2-54-19, 18 July 2019). This study's procedures conformed with the Helsinki Declaration's ethical principles for research involving human subjects. 2.1. PARTICIPANTS. Our study's sample included 75 right-handed native Turkish listeners (45 female and 30 male 20-30-year-olds, $\mathrm{M}=25.82, \mathrm{SD}=4.5$ ) who participated in the web-based sentence-picture matching task. None of the participants had any neurological or neuropsychiatric symptoms, and visual, hearing, or speech impairments. All the participants reported having normal or corrected to normal vision. Informed consent was obtained from each participant after the procedures of the survey were explained. The participants completed a demographic background questionnaire on the web-based system before the experiment, and then instructions were automatically given to them in order to run the experiment. Before the experiments began, participants had to report that a stable light and sound system were available in their environment.

2.2. MATERIAL. The experiment was prepared in PsychoPy v3.0 (Peirce, 2007) and was uploaded to the web-based platform, Pavlovia. We collected (RTs) and acceptabilityjudgment responses using a web-based sentence-picture matching task. The participants were asked to select one of two illustrations depicting either distributive or collective interpretations of the sentences. We prepared 120 sentences $(4 \times 30)$ for four experimental conditions (Table 1).

Our study has these limitations: We only focused on canonical SOV sentences to reduce the duration of the sessions, and no filler sentences were included in our experiment. ${ }^{2}$ Our

\footnotetext{
${ }^{2}$ This study is part of a larger research project that uses eye-movement tracking to investigate the on-line processing of quantifiers in Turkish. In order to make the length of the sessions manageable for the participants,
} 
experimental sentences were ordered according to their frequency scores (Aksan, Aksan, Mersinli, \& Demirhan, 2016). Table 1 shows the four experimental conditions for the factors of ORDER (every-a(n) vs. $a(n)$-every) and FOCUS (existential focus vs. universal focus).

\begin{tabular}{|c|c|}
\hline ntal sentences & Order \\
\hline \begin{tabular}{llll} 
(a) Geçen sabah sınıfta & her öğrenci & \multicolumn{2}{c}{ [BİR kitabı $]_{\mathrm{F}}$ okudu. } \\
(b) Geçen sabah sinıfta & [HER öğrenci $]_{F}$ & bir kitab1 & okudu. \\
last morning class.LOC every student.NOM a book.ACC & read.PAST.3S \\
'Last morning every student read a book at the class' & \\
\end{tabular} & $\begin{array}{l}\text { every-a(n) existential } \\
\text { every-a(n) universal }\end{array}$ \\
\hline 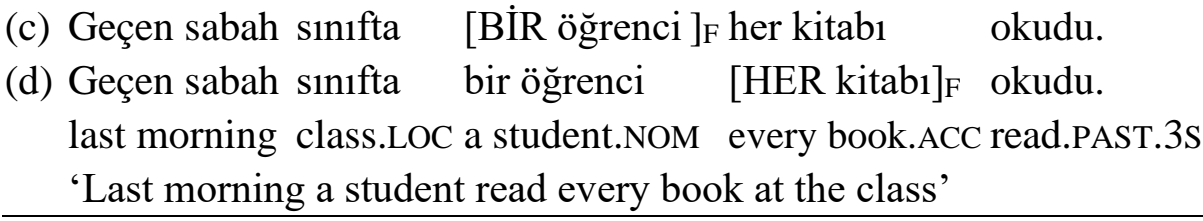 & $\begin{array}{l}a(n) \text {-every existential } \\
a(n) \text {-every universal }\end{array}$ \\
\hline
\end{tabular}

Table 1: Sample of experimental sentences of the auditory stimuli

This study used two types of stimuli: visual and auditory. The visual stimuli were created by a professional artist. The auditory stimuli were recorded using Praat v.6.1 (Boersma \& Weenink, 2006) by a trained female Turkish speaker in the Ankara University Brain Research Center (AUBRC) of Phonetics Lab. The trained female Turkish speaker was asked to produce sentences with stress on the quantifiers to meet the study's four experimental conditions. The stimuli were then evaluated by two experts for focus. As Panels A and B of Figure 1 show, the focus, which is indicated by high pitch $\left(\mathrm{H}^{*}\right)$, occurs on quantifiers in the subject or object positions. Vocalization errors and octave jumps were eliminated, and accuracy was ensured during the auditory stimuli analyses.

For the acoustical characterization of the stimuli, we segmented the auditory stimuli as shown in Figure 1. The acoustic parameters of fundamental frequency $\left(\mathrm{F}_{0}\right)$, word duration and intensity for each quantifier in the conditions were analyzed. The analysis was conducted with lmer() function in R Core Team (R) (2020) using linear mixed-effect (LME). In our LME model, word duration $(m s), \mathrm{F}_{0}(\mathrm{~Hz})$ and intensity $(\mathrm{dB})$ were the dependent variables. The model included intercepts for the two fixed factors, classic $2 \times 2$ factorial design, ORDER (levels: every- $a(n), a(n)$-every) and FOCUS (levels: existential focus, universal focus), and their interactions. Our critical segments were Segment 2 and Segment 3 where the quantifiers were positioned. Our findings for auditory stimuli indicated that FOCUS and ORDER had no significant effects (see Table 2). Post-hoc multiple comparison tests determined that there were no significant differences between the focused universal and existential quantifiers for duration $(\beta=55.66, S E=26.33, z=2.11, p=0.15)$ or intensity $(\beta=0.16, S E=0.68, z=0.24, p=0.1)$, but there were significant differences between them for $\mathrm{F}_{0}(\beta=18.27, S E=6.96, z=2.62$, $p<0.05$ ) in segment 2 . Analysis of segment 3 found no significant differences between the focused universal and existential quantifiers for duration $(\beta=5.19, S E=19.99, z=0.26, p=0.1)$, for $\mathrm{F}_{0}(\beta=-3.02, S E=8.95, z=-0.34, p=0.99)$, but there were significant differences between them for intensity $(\beta=-3.50, S E=0.65, z=-5.35, p<0.01)$.

the sentence-picture matching task did not include filler items, and we recognize this as a limitation of our study's research design. 

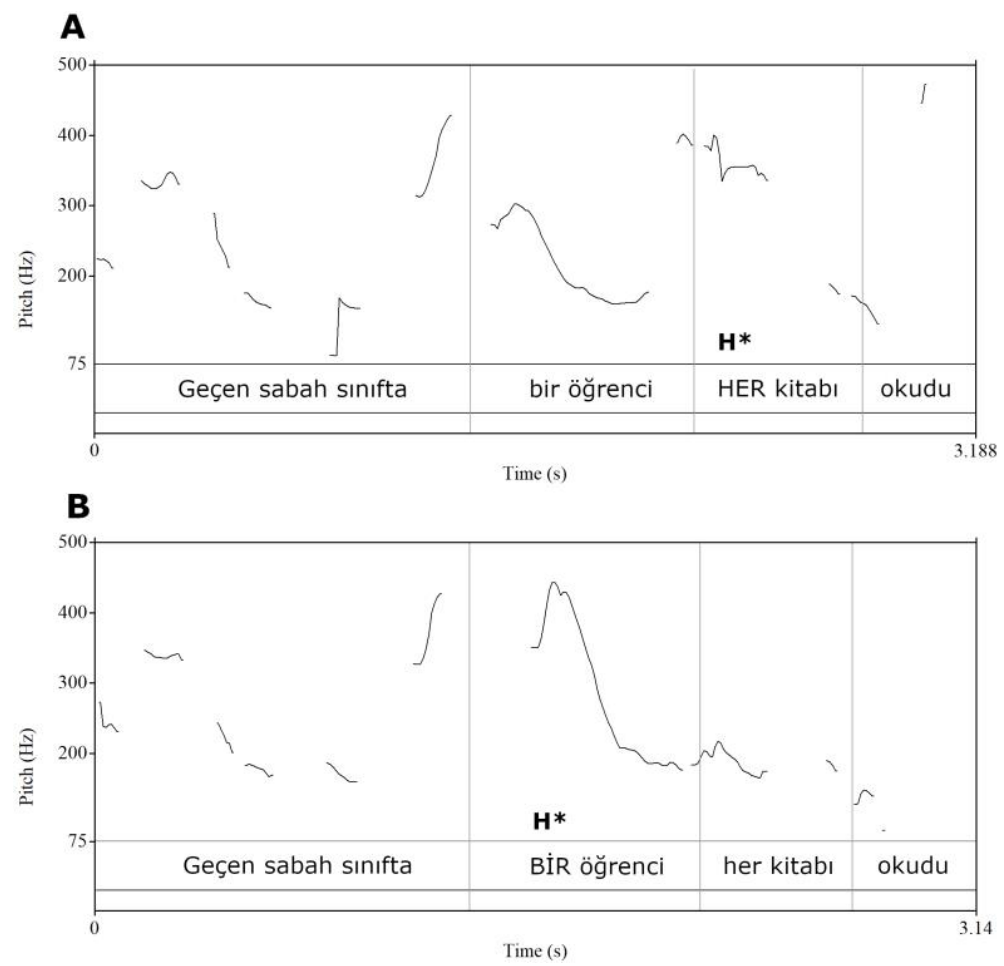

Figure 1. Two samples of pitch contour (in $\mathrm{Hz}$ ) of the sentences with $a(n)$-every order. Panel A shows a sentence with the focused universal quantifier, while Panel B displays the focused existential quantifier. Pitch accents are constituted by $\mathrm{H}$ (high) and the tone associated with the stressed syllable is constituted by ' ${ }^{*}$ ' symbol to the tone.

\begin{tabular}{lccccccccc}
\hline Seg2 & Est. & $S E$ & $t$ & $p$ & Seg 3 & Est. & $S E$ & $t$ & $p$ \\
\hline Duration & & & & & & & & & \\
Intercept & 629.50 & 51.27 & 12.28 & 0.05 & Intercept & 626.99 & 51.83 & 12.10 & 0.05 \\
Focus & -23.02 & 59.20 & -0.39 & 0.76 & Focus & -19.97 & 59.84 & -0.33 & 0.80 \\
Order & 78.68 & 59.20 & 1.33 & 0.41 & Order & -25.16 & 59.84 & -0.42 & 0.75 \\
\hline$F_{0}$ & & & & & & & & & \\
Intercept & 277.72 & 14.49 & 19.16 & 0.03 & Intercept & 224.85 & 85.28 & 2.64 & 0.23 \\
Focus & -0.08 & 16.73 & -0.01 & 1.00 & Focus & 8.42 & 98.47 & 0.09 & 0.95 \\
Order & 18.35 & 16.73 & 1.10 & 0.47 & Order & 11.44 & 98.47 & 0.12 & 0.93 \\
\hline Intensity & & & & & & & & & \\
Intercept & 65.05 & 3.04 & 21.41 & 0.03 & Intercept & 61.68 & 6.64 & 9.29 & 0.07 \\
Focus & -0.85 & 3.51 & -0.24 & 0.85 & Focus & -0.68 & 7.66 & -0.09 & 0.94 \\
Order & 1.01 & 3.51 & 0.29 & 0.82 & Order & 2.82 & 7.66 & 0.37 & 0.78 \\
\hline
\end{tabular}

Table 2: Linear Mixed-Effect (LME) results of auditory stimuli (Est.=Estimate, $S E=$ Standard error, $t=\mathrm{t}$ value, $p=$ level of significance)

2.3 PROCEDURE. Our experiment was a web-based sentence-picture matching task using visual and auditory stimuli. All the participants were asked to listen to six trial Turkish sentences before they began the experiment. As Figure 2 shows, a fixation cross (+) was displayed on screen for 500 milliseconds (ms). Then, the visual stimuli were presented for $1000 \mathrm{~ms}$ against a white background. The experimental sentences were then presented as auditory stimuli for $4000 \mathrm{~ms}$ while the pictures were still on screen. The order of stimuli was pseudo-randomized with the constraints that the same stimulus items were separated by sessions and that the same 
conditions were separated by at least four trials. The stimulus items were distributed equally among the participants.

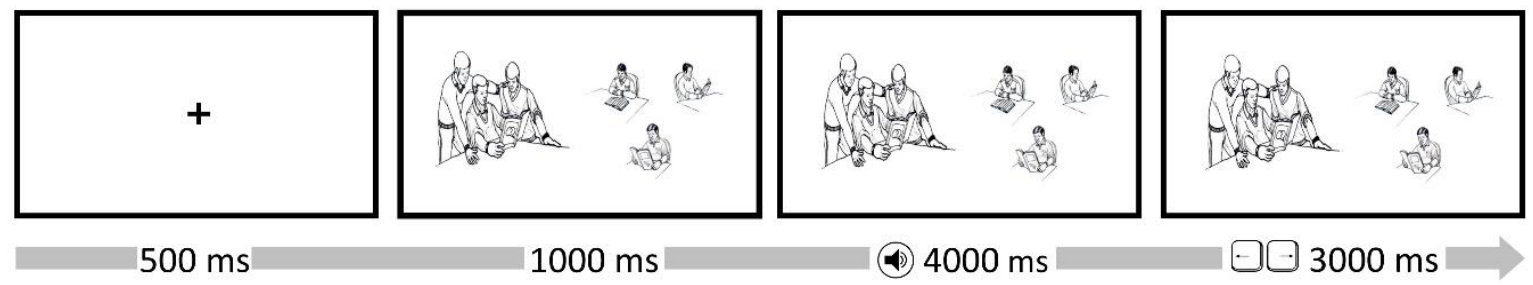

Figure 2. Visual and auditory stimuli design of experimental procedure

The participants saw the pairs of pictures in both the experimental and practice sessions. The participants listened to the sentences and examined the pictures depicting the event. Their task was to select the picture that matched the sentence by pressing either the right or the left arrow button after the sentence ended. In order not to affect response time, there was no prompt screen to tell them to select one option. The positions of the pictures were randomized. The participants' acceptance rates and RTs were recorded simultaneously. The participants were given $3000 \mathrm{~ms}$ to complete each trial. If the participants did not respond within $3000 \mathrm{~ms}$, the next trial began. There were four sessions for all the experiments, and five-minute breaks were taken by the participants after each session. Each experiment took roughly twenty minutes to complete, including the practice runs and breaks.

3. Results. The reaction times (RTs) and acceptance rates were first transformed and gathered in dplyr (Wickham, François, Henry, \& Müller, 2021) and tidyr (Wickham \& Henry, 2018) packages in R (Bates, Mächler, Bolker, \& Walker, 2015). RTs

were calculated by subtracting the time elapsed when the sentence ended from the time elapsed when the participants selected a picture. The mean plus or minus two standard deviations was used as an indicator to detect outliers. Eliminating the outliers caused a data loss of $3.4 \%$. The LME model in the lme4 package in $\mathrm{R}$ was used to analyze the logtransformed RT data. The fixed factors were ORDER (levels: every-a, a-every) and FOCUS (levels: existential focus, universal focus). The random factors were id and item $(2 \times 4)$. All the factors were analyzed using treatment coding. Pairwise comparisons were implemented using multcomp package (Hothorn, Bretz, \& Westfall, 2017). For the acceptance rates, generalized linearized mixed models (GLMMs) (Mcculloch \& Neuhaus, 2014) with the glmer() function were used with the same fixed and random factors as the RT data. The treatment coding was applied to the data, and $\mathrm{a}|\mathrm{z}|>2.0$ value indicated significance (Gelman \& Hill, 2006).

3.1. ACCEPTABILITY-JUDGMENT RESPONSES. The final model output is shown in Table 3. Our analysis indicated that the ORDER significantly affected the acceptability-judgment responses, but the effect of FOCUS was not significant, and there were no interactional effects between ORDER and FOCUS.

As Panel A of Figure 3 shows, post-hoc multiple comparison tests showed that the differences between $a(n)$-every order $(96.11 \%, \mathrm{SD}=0.19)$ and every- $a(n)$ order $(32.94 \%$, $S D=0.47)$ were significant in the sentences with focused existential quantifiers $(\beta=-4.45$, $S E=0.19, z=-23.51, p<0.001)$. The differences between $a(n)$-every order $(96.38 \%, S D=0.19)$ and every- $a(n)$ order $(25.50 \%, S D=0.44)$ in the sentences with focused universal quantifiers $(\beta=-4.95, S E=0.19, z=25.63, p<0.001)$ were also significant. Post-hoc multiple comparison indicated that the differences between the focused existential quantifiers and the focused universal quantifiers in every- $a(n)$ order $(\beta=-0.43, S E=0.16, z=-2.76, p<0.05)$ were 
statistically significant. However, the differences between the focused quantifiers in $a(n)$ every $\operatorname{order}(\beta=0.07, S E=0.21, z=0.35, p=0.99)$ were not significant.

\begin{tabular}{lccrccc}
\hline & \multicolumn{4}{c}{ Fixed Effects } & \multicolumn{3}{c}{ Random Effects } \\
\hline Parameters & \multicolumn{1}{c}{$\beta$} & \multicolumn{1}{c}{$S E$} & \multicolumn{1}{c}{$z$} & \multicolumn{1}{c}{$p$} & Id $(S D)$ & Item $(S D)$ \\
\hline (Intercept) & 3.61 & 0.18 & 19.87 & $<0.001$ & 0.84 & 0.52 \\
\hline ORDER & -4.45 & 0.19 & -23.51 & $<0.001$ & - & - \\
\hline FOCUS & 0.08 & 0.21 & 53 & 0.72 & - & - \\
\hline ORDER $\times$ FOCUS & -0.50 & 0.26 & -1.91 & 0.06 & - & - \\
\hline
\end{tabular}

Table 3: Summary of linear mixed effects models for sentence-picture match judgement (centered predictors of ORDER, FOCUS, and their interaction)

These results show that collective interpretations of the sentences with $a(n)$-every order were more acceptable than distributive interpretations $(96.38 \%$ for focused universal quantifiers and $96.11 \%$ for focused existential quantifiers). However, the participants had a greater tendency to interpret the sentences with every- $a(n)$ order as distributive $(74.50 \%$ for focused universal quantifiers and $67.06 \%$ for focused existential quantifiers).
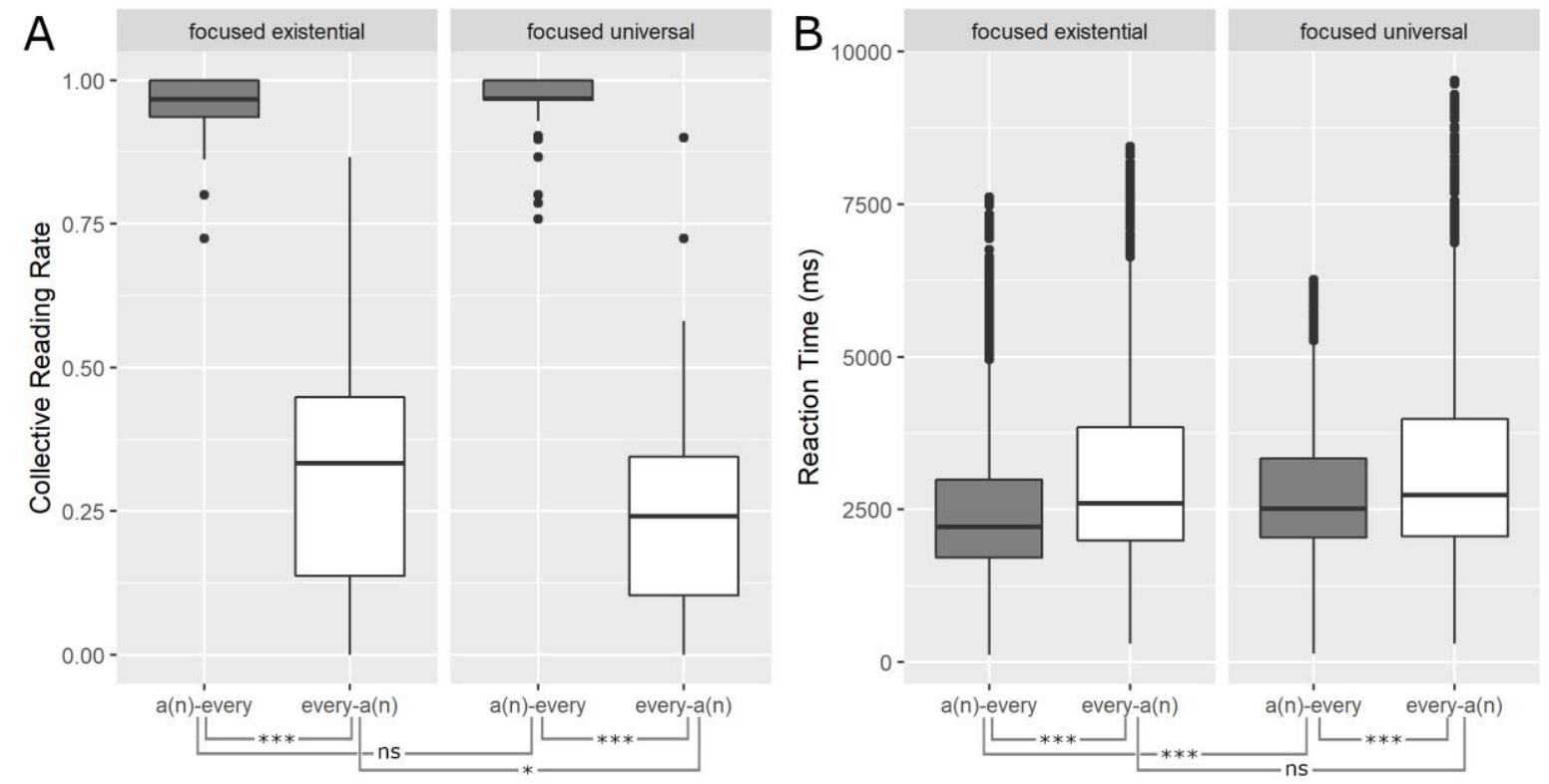

Figure 3. Mean collective reading rates (A) and mean RTs (B) for all participants for per condition.

3.3 REACTION TIMES. The LME analysis (Table 4) indicated that the main effects of ORDER and FOCUS significantly affected RTs. There were also significant interactions between ORDER and FOCUS. As Panel B of Figure 3 shows, post-hoc multiple comparison determined that there were statistically significant differences between $a(n)$-every order $(2507 \mathrm{~ms}, S D=1246)$ and every- $a(n)$ order (3088 ms, $S D=1554)$ in the sentences with focused existential quantifiers $(\beta=-0.17, S E=0.21, z=-7.91, p<0.001)$. Statistically significant differences were also found between $a(n)$-every order $(2758, S D=1088)$ and every- $a(n)$ order $(3237 \mathrm{~ms}, S D=1684)$ in the sentences with focused universal quantifiers $(\beta=-012, S E=0.03, z=-4.01, p<0.001)$. The differences between focused existential quantifiers and focused universal quantifiers were significant in $a(n)$-every order $(\beta=-0.14, S E=0.16, z=-4.56, p<0.001)$, resulting in a significant main effect for FOCUS. However, there were no statistically significant differences between 
focused existential quantifiers and focused universal quantifiers in every- $a(n)$ order $(\beta=-0.04$, $S E=0.03, z=-1.40, p=0.16)$.

\begin{tabular}{lcccccc}
\hline & \multicolumn{4}{c}{ Fixed Effects } & \multicolumn{2}{c}{ Random Effects } \\
\hline Parameters & $\beta$ & \multicolumn{1}{c}{$S E$} & \multicolumn{1}{c}{$t$} & \multicolumn{1}{c}{$p$} & $\operatorname{Id}(S D)$ & Item $(S D)$ \\
\hline (Intercept) & 7.72 & 0.03 & 225.05 & $<0.001$ & 0.04 & 0.11 \\
\hline ORDER & 0.21 & 0.03 & 7.17 & $<0.001$ & - & - \\
\hline FOCUS & 0.14 & 0.03 & 4.56 & $<0.001$ & - & - \\
\hline ORDER $\times$ FOCUS & -0.09 & 0.04 & -2.32 & $<0.05$ & - & -
\end{tabular}

Table 4: Summary of linear mixed effects models for reaction times (centered predictors of order, focus and their interaction)

The discrepancy in the participants' judgments of every- $a(n)$ order indicated ambiguity. Therefore, we conducted an additional analysis with the participants' responses divided into collective readings and distributive readings. In the group of collective readings, the difference between focused existential quantifiers (3453 ms, $S D=1801)$ and focused universal quantifiers (3893 ms, $S D=2032$ ) was significant: $\beta=0.10, S E=0.04, t=2.53, p<0.05$. On the other hand, the difference between focused existential quantifiers ( $3065 \mathrm{~ms}, S D=1676)$ and focused universal quantifiers (3089 ms, $S D=1654$ ) in the second group of distributive readings was not statistically significant: $\beta=0.001, S E=0.02, t=0.27, p=0.79$.

The interpretation of sentences with every- $a(n)$ order had longer RTs than those with $a(n)$-every order, and the interpretation of the every-a(n) order sentences with focused universal quantifiers had longer RTs than the interpretation of the every- $a(n)$ order sentences with focused existential quantifiers. Similarly, the every- $a(n)$ order sentences with focused universal quantifiers had longer RTs than the every- $a(n)$ order sentences with focused existential quantifiers in the group of accepted collective readings.

4. Discussion. Our study investigated the disambiguation processes for the existential quantifier bir 'a/an' and the universal quantifier her 'every' in terms of their syntactic and prosodic features in Turkish sentences. For this purpose, we collected acceptance rates and RT data using a web-based sentence-picture matching experiment. We wanted to determine how the syntactic and prosodic information affect interpretation preferences in quantifier resolution.

Our first research question was whether linearity plays a crucial role in the interpretation of scope-ambiguous doubly quantified sentences in Turkish. The sentences with every- $a(n)$ order in Turkish were, in accordance with previous claims in the literature, found to be scopally ambiguous between collective and distributive reading (Aygen-Tosun, 2007; Enç, 1991; Kelepir, 2001; Kural, 1992). It is important to note that there was a greater tendency toward interpreting the sentences with every- $a(n)$ order as distributive. These findings confirm the suggestion that the inverse scope reading is available in sentences with the accusative marking indefinite direct objects that are ambiguous between wide scope and narrow scope readings (Aygen-Tosun, 2007; Enç, 1991; Kelepir, 2001; Kural, 1992). On the other hand, we found that sentences with $a(n)$-every order do not have a multiple interpretation, that is, the collective interpretation of sentences with $a(n)$-every order was clearly judged to be more acceptable than the distributive interpretation. This finding supports the claim that linearity plays a role in the scope of quantifiers in Turkish (Göksel, 1998). Of the empirical studies of quantifier ambiguity in Turkish, Gürer's (2015) study claimed that the indefinite always takes scope over the universal quantifier in the $a(n)$-every order in SOV sentences. Ay and Aydin 
(2016) suggested that native speakers of Turkish prefer surface scope readings over inverse scope readings. These suggestions may support our results for the initial role of linearity in disambiguation.

Our second question was whether prosody affects universal and existential quantifier ambiguity in Turkish sentences. Although there was no main effect of focus concerning acceptability-judgment rates, our post-hoc analyses found an effect of focus in scopally ambiguous structures (every-a(n) order). There was a greater tendency toward interpreting sentences with every- $a(n)$ order as distributive when universal quantifiers were focused (74.50\%) than when existential quantifiers were focused $(67.06 \%)$. Therefore, the inverse scope reading was preferred when the universal quantifier object was focused in sentences with every- $a(n)$ order. These findings seem to confirm the claim by Kennelly (2003) that there is no unique factor such as linearity that induces quantifier dependencies. Although her data did not include scopally ambiguous structures with every- $a(n)$ order, our analysis of these types of sentences also indicates that prosody (namely, discourse structure) plays a role in accounting for quantifier scope ambiguity. These findings concerning prosodic information support the previous empirical assumptions in the psycholinguistic literature for a variety of languages (Baltazani, 2002; Golcher \& Alexiadou, 2020; Ionin \& Luchkina, 2018; Keller \& Alexopoulou, 2001; Oikonomou et al., 2020). Surányi and Turi’s (2017) off-line acceptability-judgment study proposed that preverbal distributive numeral phrases have similar interpretational effects whether or not they are focus phrases. This was found to be the case for both wide and narrow scopes in Hungarian sentences. Our finding on the effects of focus marking partially supports Gürer's (2015) and Altınok's (2017) off-line acceptabilityjudgment studies. Gürer claimed that the inverse scope reading is available regardless of the position of focus and that focus thus has no direct effect on quantifier scope. Altinok also found no significant difference between prosodic and marked contour in inverse scope readings. Thus, Altınok argued that language-specific features such as scope rigidity for Turkish disallow prosodical effects on interpretation.

Our third research question was whether prosody has any effect on the interpretation processing performance of sentences with every- $a(n)$ order. Our study's acceptabilityjudgment responses indicated that only the sentences with every- $a(n)$ order involve the resolution of quantifier scope ambiguities. This is why we conducted an additional analysis with the participants' responses divided into collective readings and distributive readings. Our findings from the RT data indicated that computing the interpretation of the sentences with focused universal quantifiers involved significantly more cognitive load than computing the interpretation of the sentences with focused existential quantifiers for the participants who accepted collective readings, which were not the salient reading. These findings are compatible with previous findings that there is a greater tendency toward interpreting the sentences with every- $a(n)$ order as collective when existential quantifiers are focused than when universal quantifiers are focused. This means that the sentences with every- $a(n)$ order and focused existential quantifiers were preferred for collective readings by the participants and required less processing time.

Our RT data showed that computing the interpretation of sentences with every-a(n) order involved significantly more cognitive load than computing the interpretation of sentences with $a(n)$-every order, which answered our fourth research question affirmatively. This finding confirms the results of an eye-movement study by Filik et al. (2004), which determined that singular and plural references affected quantifier resolution. Our data for syntactic position supports their study's claim that universal-existential quantifier order takes longer to process than existential-universal quantifier order in English sentences. 
Our findings about scopally ambiguous structures (every- $a(n)$ order) support Kurtzman and Macdonald's (1993) suggestion that multiple processing mechanisms (e.g., minimal attachment and local association) could be involved in ambiguity resolution. We found that every- $a(n)$ order was still ambiguous for Turkish listeners. Therefore, we think that multiple strategies are in fact used during interpretation. This claim is supported by both our percentages of acceptability-judgment responses and our RT data. The more the percentages of interpretation bias rose, the longer the RTs. This result is in line with the psycholinguistic literature (Tunstall, 1998; Frazier et al., 1999; Brasoveanu \& Dotlačil, 2021) and supports the idea of multiple strategies. Our findings also indicated that the participants preferred the collective reading in $a(n)$-every order. This finding supports the conclusions of Brasoveanu and Dotlačil's self-paced reading study. They claimed that there are multiple events in distributive readings, but only one event to interpret and process in collective readings. This may be why the participants preferred the collective reading over the distributive reading. This suggestion may also apply to the high acceptance percentages for the collective reading.

\section{References}

Aksan, Yeşim, Aksan, Mustafa, Mersinli, Ümit, \& Demirhan, Umut U. 2016. A frequency dictionary of Turkish. London: Routledge. https://doi.org/10.4324/9781315733302

Altınok, Dursun. 2017. Quantifier Scope and Prosody in Turkish. Utah: The University of Utah. Unpublished doctoral dissertation. https://collections.lib.utah.edu/details?id=1440101

Anderson, Catherine. 2004. The structure and real-time comprehension of quantifier scope ambiguity. Illinois: Northwestern University. Unpublished doctoral dissertation. http://aix1.uottawa.ca/ canderso/diss/AndersonDiss.pdf

Ay, Sıla \& Aydın, Özgür. 2016. Someone judges every sentence. In Ayşe Gürel (ed.), Second Language Acquisition of Turkish. 135-163. Amsterdam: John Benjamins Publishing. https://doi.org/10.1075/lald.59.06ay

Aygen-Tosun, Gülşat. 2007. Specificity and subject-object positions/scope interactions in Turkish. Dil ve Edebiyat Dergisi 4(2). 1-31. http://ded.mersindilbilim.info/en/pub/issue/19499/207807

Baltazani, Mary. 2002. The prosodic structure of quantificational sentences in Greek. In Mary Andronis, Erin Debenport, Anne Pycha, and Kimihiro Yoshimura (eds.), Proceedings of the 38th meeting of the Chicago Linguistic Society. 63-78. Chicago: Chicago Linguistic Society. http://users.uoi.gr/mbaltaz/en/cls2002.pdf

Bates, Douglas, Mächler, Martin M., Bolker, Ben, \& Walker, Steve. 2015. 1me4: Linear mixed-effects models using Eigen and S4. R Package Version 1.1-7.

Boersma, Paul \& David Weenink. 2006. Praat: Doing phonetics by computer. Retrieved from http://www.praat.org/.

Bott, Oliver \& Radó, Janina. 2009. How to provide exactly one interpretation for every sentence, or what eye movements reveal about quantifier scope. The fruits of empirical linguistics 1, 25-46. https://doi.org/10.1515/9783110216141.25

Brasoveanu, Adrian \& Dotlačil, Jakup. 2019. Quantification. In Chris Cummins \& Napolean Katsos (eds.), The Oxford Handbook of Experimental Semantics and Pragmatics. 228246. Oxford, UK: Oxford University Press. https://doi.org/10.1093/oxfordhb/9780198791768.013.3

Dotlačil, Jakub \& Brasoveanu, Adrian. 2021. The representation and processing of distributivity and collectivity: Ambiguity vs. underspecification. Glossa: A journal of general linguistics 6(1). 1-22. https://doi.org/10.5334/gjgl.1131

Dwivedi, V. D. (2013). Interpreting quantifier scope ambiguity: Evidence of heuristic first, algorithmic second processing. PloSone 8(11). e81461.

https://doi.org/10.1371/journal.pone.0081461 
Enç, Mürvet. (1991). The semantics of specificity. Linguistic Inquiry 22(1). 1-25. https://www.jstor.org/stable/4178706?origin=JSTOR-pdf

Filik, Ruth, Paterson, Kevin B., \& Liversedge, Simon P. 2004. Processing doubly quantified sentences: Evidence from eye movements. Psychonomic Bulletin \& Review 11(5). 953-959. https://doi.org/10.3758/BF03196727

Fodor, Janet D. \& Sag, Ivan A. 1982. Referential and quantificational indefinites. Linguistics and Philosophy 5(3). 355-398. https://doi.org/10.1007/BF00351459

Frazier, Lyn, Patch, Jeremy M., \& Rayner, Keith. 1999. Taking on semantic commitments, II: collective versus distributive readings. Cognition 70. 87-104. http://doi.org/10.1016/S00100277(99)00002-5

Gelman, Andrew \& Hill, Jennifer. 2006. Data analysis using regression and multilevel/hierarchical models. Cambridge: Cambridge University Press. https://doi.org/10.1017/CBO9780511790942

Göksel, Asl1. 1998. Linearity, focus and the postverbal position in Turkish. In Lars Johanson (ed.), Mainz Meeting Proceedings of the Seventh International Conference on Turkish Linguistics. 85-106. Wiesbaden: Harrassowitz Verlag.

Gürer, Asl1. 2015. Semantic, prosodic, and syntactic marking of information structural units in Turkish. İstanbul: Boğaziçi University. Unpublished doctoral dissertation.

Hothorn, Torsten, Bretz, Frank, \& Westfall, Peter. 2017. Simultaneous inference in general parametric models. Package 'multcomp'. Simultaneous inference in general parametric models. Projects for Statistical Computing. Vienna: Austria. http://cran.stat.sfu.ca/web/packages/multcomp/multcomp.pdf

Ionin, Tania \& Luchkina, Tatiana. 2018. Focus on Russian scope: An experimental investigation of the relationship between quantifier scope, prosody, and information structure. Linguistic Inquiry 49(4). 741-779. https://doi.org/10.1162/ling_a_00288

Ioup, Georgette. 1975. Some universals for quantifier scope. Syntax and Semantics 4. 37-58. https://doi.org/10.1163/9789004368828_003

Kelepir, Meltem. 2001. Topics in Turkish syntax: Clausal structure and scope. Cambridge: Massachusetts Institute of Technology. Unpublished doctoral dissertation. http://hdl.handle.net/1721.1/8196

Keller, Frank and Alexopoulou, Theodora. 2001. Phonology competes with syntax: Experimental evidence for the interaction of word order and accent placement in the realization of information structure. Cognition 79(3). 301-372. https://doi.org/10.1016/S0010-0277(00)00131-1

Kural, Murat. 1992. Properties of Turkish scrambling. Los Angeles: UCLA. Unpublished MA thesis. https://scholarworks.umass.edu/nels/vol22/iss1/18

Kurtzman, Howard S. \& MacDonald, Maryellen C. 1993. Resolution of quantifier scope ambiguities. Cognition 48(3). 243-279. https://doi.org/10.1016/0010-0277(93)90042-t.

McCulloch, Charles E. \& Neuhaus, John M. 2014. Generalized linear mixed models. Wiley StatsRef: Statistics Reference Online. https://doi.org/10.1002/9781118445112.stat07540

Oikonomou, Despina, Golcher, Felix, \& Alexiadou, Artemis. 2020. Quantifier scope and information structure in Greek. Glossa: A Journal of General Linguistics 5(1). 1-36. https://doi.org/10.5334/gjgl.1183

Pavlovia. https://pavlovia.org/ (accessed on 23 March 2020).

Pierce, Jonathan W. 2007. PsychoPy-psychophysics software in Python. Journal of Neuroscience Methods 162(1-2). 8-13. https://doi.org/10.1016/j.jneumeth.2006.11.017

R Core Team. 2020. R: A language and environment for statistical computing. R Foundation for Statistical Computing. Vienna: Austria. Retrieved from https://www.R-project.org/ 
Scontras, Gregory, Polinsky, Maria, Tsai, C.-Y. Edwin, \& Kenneth, Mai. 2017. Crosslinguistic scope ambiguity: When two systems meet. Glossa: A Journal of General Linguistics 2(1): 36. 1-28. https://doi.org/10.5334/gjgl.198

Surányi, Balázs \& Turi, Gergő. 2017. Focus and quantifier scope: An experimental study of Hungarian. In Harry van der Hulst \& Anikó Lipták (eds.), Approaches to Hungarian, Papers Presented in the 2015 Leiden Conference. 209-238. Amsterdam: John Benjamins Publishing. https://doi.org/10.1075/atoh.15.08sur

Tunstall, Susanne L. 1998. The interpretation of quantifiers: Semantics and processing. Amherst: University of Massachusetts at Amherst. Unpublished doctoral dissertation. https://scholarworks.umass.edu/dissertations/AAI9909228

Wickham, Hadley \& Henry, Lionel. 2018. tidyr: Easily Tidy Data with 'spread () 'and' gather ()' functions. R Package Version 0.8.0.

Wickham, Hadley, François, Romain, Henry, Lionel, \& Müller, Kirill. 2021. dplyr: A grammar of data manipulation. R Package Version 1.0.

Zimmermann, Malte \& Philipp, Mareike. 2019. Empirical investigations on quantifier scope ambiguities in German. In Michael Franke, Nikola Kompa, Mingya Liu, Jutta Mueller, \& Juliane Schwab (eds.), Proceedings of Sinn und Bedeutung. 24(2):145-164. Osnabrück: Osnabrück University Press. https://semanticsarchive.net/Archive/mZhNDA4Y/SuB24twovolume.pdf 